\title{
C-Shape Microstrip Patch for Dual Band on Different Shape Ground Plane
}

\author{
Madhavi Bagal \\ M. S. Bidwe Collage of Engineering, Latur
}

\author{
S. S. Killarikar \\ M. S. Bidwe Collage of Engineering, Latur
}

\begin{abstract}
The objective of this paper is to design an inset fed dual band rectangular microstrip patch antenna symmetrical ground plane. In this paper we simulated our design by using the electromagnetic solver, simulator (IE3D), was used to numerically investigate and optimize the proposed antenna configuration. Besides the structure external dimensions, the influence of the various antenna parameters on the resonant behavior have been observed. It has been found that the symmetrical position of patch over ground plane have clear impact on overall antenna performance. Many antenna structures have been modeled to demonstrate the effects of these parameters on the resulting dual band response. we design antenna for $(1.85-2.05 \mathrm{GHz})$ and upper band $(2.35$ $2.44 \mathrm{GHz})$.
\end{abstract}

\section{Keywords}

Microstrip antenna; IE3D SIMULATOR; Dielectric; Patch width; Patch Length; Losses; strip width; strip length.

\section{INTRODUCTION}

Ahmed H. Reja [1] proposed Study of Micro Strip Feed Line Patch Antenna experimentally increase the Return Loss $33.60 \mathrm{~dB}$ at $2.5 \mathrm{GHz}$ frequency and VSWR is 1.5 by using CAD for RT DUROID 5880. Santanu Kumar Behera and Y. Choukiker [2] proposed Design and Optimization of Dual Band Micro Strip Antenna using Practical Swarm Optimization maximize the return loss for dual band Frequency at $2.4 \mathrm{GHz}$ is $-43.9 \mathrm{~dB}$ and at $3.08 \mathrm{GHz}$ is $-27.4 \mathrm{~dB}$. M. A. S. Alkanhal[3] proposed microstrip antenna by integrating various shapes to get reduced size and maintain performance of antenna for triple band. A A Deshmukh and G Kumar [4] proposed compact L-Shape patch broadband Microstrip antenna experimentally increase bandwidth up to 13.7\%. Z M Chen [5] further increase bandwidth of this antenna up to $23.7 \%-24.43 \%$. K F Lee [6] proposed U Shape slot shorting post small size Microstrip Antenna and increase bandwidth up to $42 \%$. S C Gao [7] used uniplanar photonic band gap structure for enhancing band width and gain. M Khodier [8] New wideband stacked microstrip antennas for enhancing band width. Major issue for micro strip antenna is narrow Bandwidth. Asymmetrical patch on ground plane affect overall performance of antenna. $\mathrm{K}$. Song et. al [10] designed asymmetrical L-shaped patch antenna for UWB application with $-10 \mathrm{~dB}$ return loss and peak gain 2.22 to $6.1 \mathrm{dBi}$ for operating bandwidth 3.01-11.30 $\mathrm{GHz}$ frequency.
In this paper we tested our design by using electromagnetic simulator (IE3D). IE3D is an integral equation, method of moment, full-wave electromagnetic simulator. It includes layout editor, electromagnetic simulator, schematic editor and circuit simulator, near field calculation program, format converter, current and field display program. IE3D employs a 3D non-uniform triangular and rectangular mixed meshing scheme. It solves the current distribution, slot-field distribution, network parameters, and radiation patterns, near field on an arbitrarily shaped and oriented 3D metallic structure in a multi-layered dielectric environment.

Researchers are focusing on how to design microstrip antennas for various band. Due to its advantages such as lowcost, small size low weight and capability to integrate with Microwave integrated circuits, the microstrip patch antenna is a very good candidate for integrations in applications such as wireless communication systems, mobile phones and laptops. In this paper a C-slot microstrip antenna with two symmetrical strip (Figure 1) is designed and simulated for the frequency range of $1.85-2.35 \mathrm{GHz}$. This antenna presents an extension to the single C-slot antenna presented at LAPC $2009[8,9]$. The proposed antenna has a gain of $4 \mathrm{dBi}$ and presents a size reduction of $33 \%$ when compared to a conventional square microstrip patch antenna. Extensive simulation results using Advanced Design Systems by Agilent (uses the MOM method) will be presented.

\section{PROPOSED DESIGN}

The results of proposed dual band microstrip patch antenna verified in IE3D Simulator with optimization. The initial antenna is shown in Figure 1. It consists of a c-slot at each end and placed within the patch [7]. The resulting antenna structure has the following parameters; the patch shape length $\mathrm{L}_{\mathrm{p}}=28.6 \mathrm{~mm}$, and its width $\mathrm{W}_{\mathrm{p}}=24.4 \mathrm{~mm}$. The size of the ground plane has been found to be of $\mathrm{L}_{\mathrm{g}}=35 \mathrm{~mm}$ and $\mathrm{W}_{\mathrm{g}}=$ $24.6 \mathrm{~mm}$. The height of substrate is $\mathrm{h}=1.57 \mathrm{~mm}$ and dielectric constant $\varepsilon_{\mathrm{r}}=4.34$. A $50 \Omega$ inset microstripline feed is attached to the microstrip and has a width $\mathrm{W}_{\mathrm{f}}=2.82 \mathrm{~mm}$ and length $\mathrm{L}_{\mathrm{f}}$ $=42.8 \mathrm{~mm}$. The length and width of c-slot is $21 \mathrm{~mm}$ and $1 \mathrm{~mm}$ respectively and also length and width of slot at top of c-slot is $21 \mathrm{~mm}$ and $2 \mathrm{~mm}$ respectively.

We will conduct a simulation study on the structure of Figure 1 by adjusting the dimension of ground plane. Initially we put ground position for entire patch. As we reduce ground material, it is found that return loss is getting reduced from $16 \mathrm{~dB}$ to $-27 \mathrm{~dB}$. 


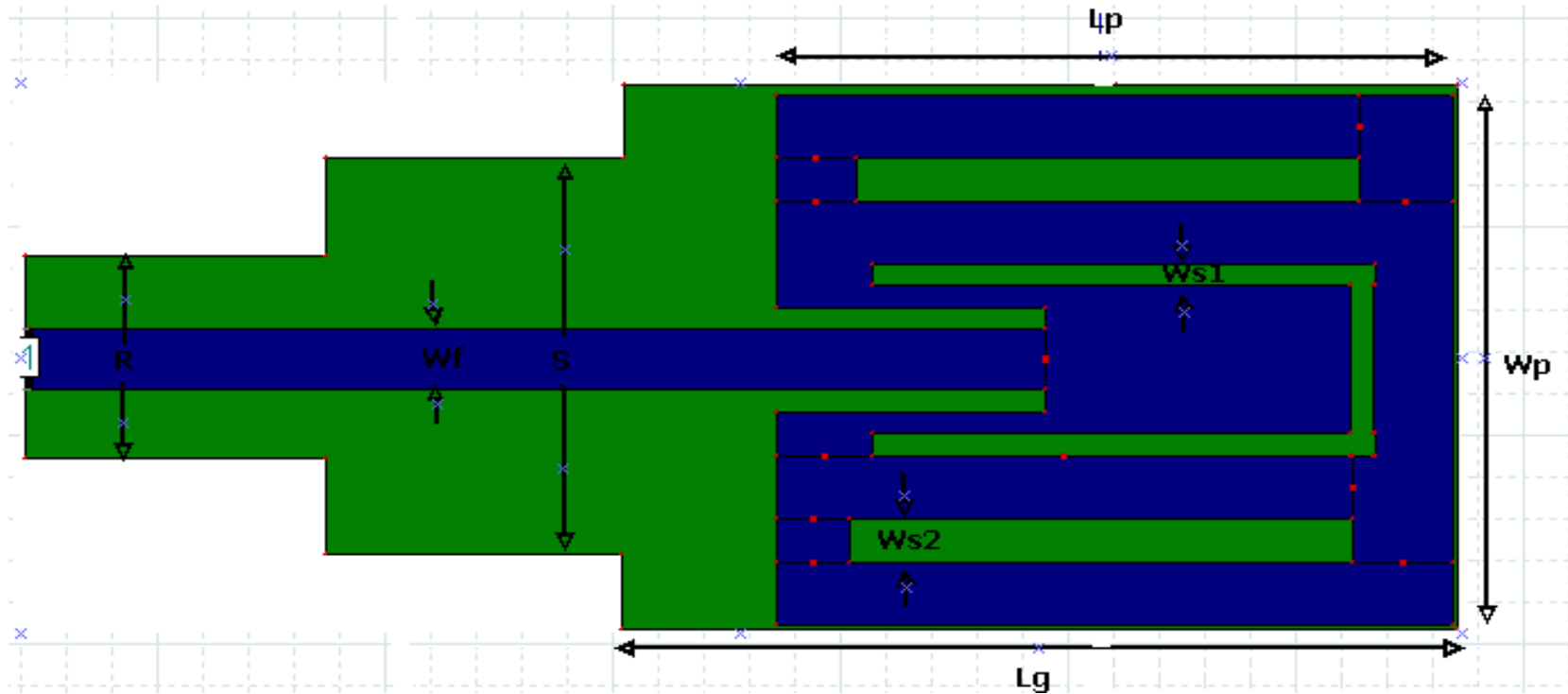

Figure 1. Proposed antenna design

Table 1. Changing shape of patch on ground( Changing $\mathbf{S}$ )

\begin{tabular}{|c|c|c|}
\hline $\begin{array}{c}\text { Ground } \\
\text { adjustment at } \mathbf{S} \\
(\mathbf{m m})\end{array}$ & $\begin{array}{c}\text { Resonant } \\
\text { frequency }(\mathbf{G H z})\end{array}$ & $\begin{array}{c}\text { Return Loss } \\
\left(\mathbf{S}_{\mathbf{1 1}} \text { in dBm) }\right.\end{array}$ \\
\hline 24.4 & 1.80 & -4.11 \\
\hline 23.4 & 1.85 & -5.2 \\
\hline 22.4 & 1.90 & -8.33 \\
\hline 21.4 & 1.95 & -10.04 \\
\hline 18.2 & 2.0 & -14.8 \\
\hline 17.4 & 2.05 & -12.8 \\
\hline 16.4 & 2.1 & -9.07 \\
\hline
\end{tabular}

The patch length on ground from left side matching is increased tremendously, presented in table 1 and table 2 for first and second band respectively. As we decrease the parameter S, that is width of ground, the resonant frequency at $2.4 \mathrm{GHz}$ is not affected much but the matching is increased tremendously as shown in Table I. but return loss at $1.95 \mathrm{GHz}$ is decreases. Similarly as we decrease $\mathrm{R}$ that is width of patch as shown in figure 1 , return loss at frequency $2.4 \mathrm{GHz}$ decreases up to $-27 \mathrm{~dB}$ and gain of antenna is $4 \mathrm{~dB}$. Figure 2 depicts the resulting return loss responses before cutting ground plane i. e. initial ground plane.

From Figure 2, it observed that we get first band with sufficient return loss, the resulting return loss responses obtained by reducing ground polane from left to right on ground plane presented in table 1 and table 2. Also current distribution for first and second band is presented in figure 3 .

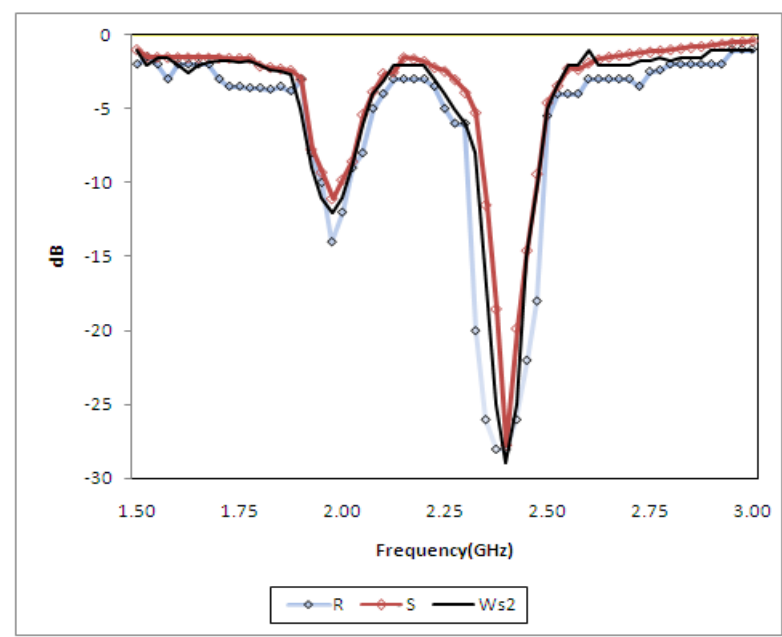

Fig 2: Return loss of antenna for variation in ground plane

Table 2. Changing shape of patch on ground (Changing R)

\begin{tabular}{|c|c|c|}
\hline $\begin{array}{c}\text { Patch adjustment } \\
\text { on ground from } \\
\text { Left of patch } \\
\text { (mm) }\end{array}$ & $\begin{array}{c}\text { Resonant } \\
\text { frequency(GHz) }\end{array}$ & $\begin{array}{c}\text { Return Loss } \\
\text { (S }_{\mathbf{1 1}} \text { in dBm) }\end{array}$ \\
\hline 24.4 (Initial) & 1.8 & -4.23 \\
\hline 23 & 1.9 & -6.32 \\
\hline 20 & 2.2 & -8.45 \\
\hline 17 & 2.25 & -12.56 \\
\hline 14 & 2.3 & -16.09 \\
\hline 11 & 2.35 & -21.9 \\
\hline 9 & 2.4 & -27.88 \\
\hline 6 & 2.45 & -25.06 \\
\hline 3 & 2.5 & -10.71 \\
\hline
\end{tabular}


Figure 3 depicts the resulting current distribution for first band that is we present current distribution at $2.4 \mathrm{GHz}$ frequency since return loss at this frequency is -27.88 . The current distribution for is also presented in figure 3 that is the resulting current distribution for second band that is at 1.95 $\mathrm{GHz}$ since return loss at this frequency is -10.04 . Gain of antenna at $2.4 \mathrm{GHz}$ is $4 \mathrm{dBi}$ and radiation pattern of antenna as presented in figure 4 and figure 5 respectively.

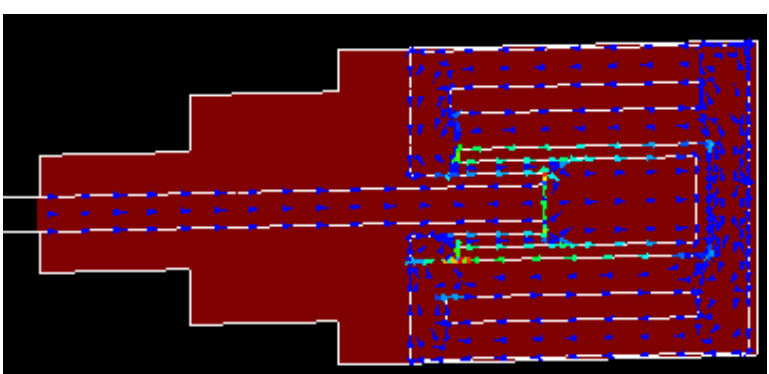

Figure 3. Current distribution

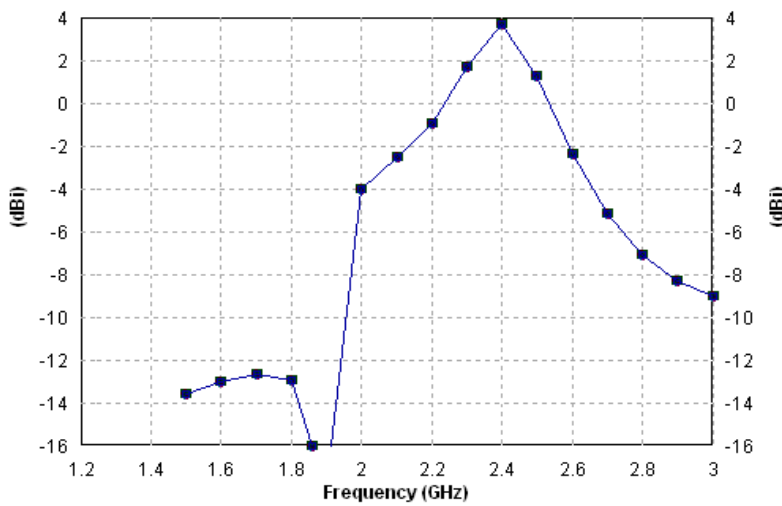

Figure 4. Gain Vs Frequency (in GHz)

Results of the variation of the size of the ground plane, as Figure 1 implies, show that the dual band response deteriorates for ground plane width other than the reference value. However, dual-band responses are obtained with increased or decreased higher resonating bands. The effect of the width of ground, has been demonstrated in Figure 2 and ,table 1 and 2 in terms of return loss. For larger values of the width of ground, the antenna offers a one-band resonant behavior, and the dual-band resonance occurs as the width is made smaller and approaches that of the reference antenna.

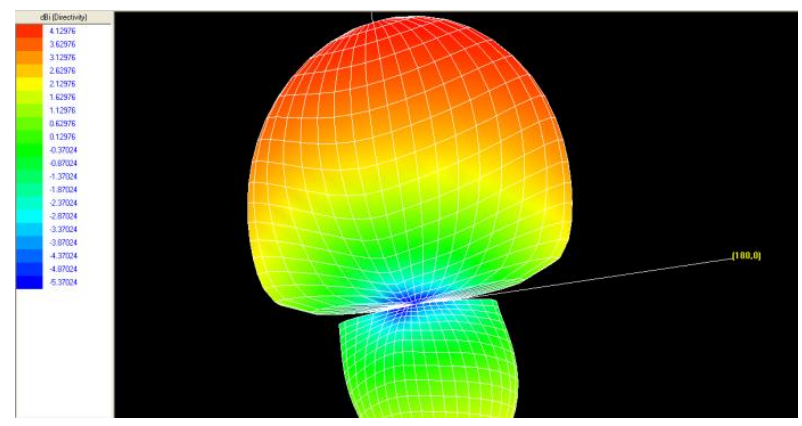

Figure 5. Elevation Pattern at E-total

\section{CONCLUSION}

An C-shaped dual band antenna is presented in this paper, as a candidate for use for two band that is $(1.85-2.05 \mathrm{GHz})$ and $(2.35-2.44 \mathrm{GHz})$. The antenna has been modeled and its performance has been analyzed using a method of moment based software, IE3D. The proposed antenna has been found to possess a miniaturized size and a width making it suitable for compact size dual band applications. The simulated results of IE3D at $2.4 \mathrm{GHz}$ is Return loss $=-27 . \mathrm{dB}$ and at $1.95 \mathrm{GHz}$ Return loss $=-14 \mathrm{~dB}$. VSWR at $2.4 \mathrm{GHz}$ is 1.82 , Directivity $=6 \mathrm{dBi}$, Gain $=4 \mathrm{dBi}$ at $2.4 \mathrm{GHz}, 3 \mathrm{~dB}$ beam width $=35.5575$ degrees, Mismatch loss $=-0.0289842 \mathrm{~dB}$ is very low, Efficiency $=90 \%$. The proposed antenna fabricated on FR4 substrate, E-Shaped multiband microstrip antenna effective work on $2.4 \mathrm{GHz}$ the proposed antenna work very effectively for wireless communication.

\section{REFERENCES}

[1] Ahmed H. Reja "Study of Micro Strip Feed Line Patch Antenna", Antennas and Propagation International Symposium, vol. 27, pp. 340-342 December 2008.

[2] Sahntanu Kumar Behera and Y. Choukiker, "Design and Optimization of Dual Band Micro Strip Antenna Using Practicle Swarm Optimization Technique," Springer Science Business Media, LLC, pp. 1346-1354, 2010

[3] M. A. S. Alkanhal, "Compact composite triple band antenna", Progress In Electromagnetics Research, PIER 93, 221-236, 2009

[4] A. A. Deshmukh and G. Kumar, "Compact broadband gap-coupled shorted L-shaped microstrip antennas," IEEE Antennas and Propagation International Symposium, vol 1, (Baltimore, Maryland), pp. 106-109, IEEE, July 2001.

[5] Z. M.Chen and Y. W. M. Chial, "Broadband probe-fed L-shaped plate antenna," Microwave and Optical Technology Letters, vol. 26, pp. 204-206, 1985.

[6] K. F. Lee, K. M. Luk, K. F. Tong, Y. L. Yung, and T. Huynh, "Experimental study of the rectangular patch with a U-shaped slot," IEEE Antennas and Propagation International Symposium, vol.1, (Baltimore, Maryland), pp. 10-13, IEEE, July 1996.

[7] S. C. Gao, L. W. Li, M. S. Leong, and T. S. Yeo, "Design and analysis of a novel wideband microstrip antenna," IEEE Antennas and Propagation International Symposium,vol.1, (Boston, Massachusetts), pp. 90-93, IEEE, July 2001.

[8] M. Khodier and C. Christodoulou, "A technique to further increase the bandwidth Of stacked microstrip antennas," IEEE Antennas and Propagation International Symposium, vol. 3, pp. 1394-1397, IEEE, July 2000.

[9] Neenansha Jain, Anubhuti Khare, Rajesh Nema, "EShape Micro strip Patch Antenna on Different Thickness for pervasive Wireless Communication", International Journal of Advanced Computer Science and Applications, Vol. 2, No. 4, 2011

[10] K. Song, Y.-Z. Yin, S.-T. Fan, and B. Chen," compact open ended L-shaped slot antenna with asymmetrical rectangle patch for UWB application", Progress In Electromagnetics Research C, Vol. 19, 235-243, 2011 